\title{
A market-shaping approach for the biopharmaceutical industry: governing innovation towards the public interest
}

Mariana Mazzucato and Henry Lishi Li

\begin{abstract}
Enhancing research and development, and ensuring equitable pricing and access to cuttingedge treatments, are both vital to a biopharmaceutical innovation system that works in the public interest. However, despite delivering numerous therapeutic advances, the existing system suffers from major problems: a lack of directionality to meet key needs; inefficient collaboration; high prices that fail to reflect the public contribution; and an overly financialised business model. COVID-19 has magnified and focalized these challenges. We review these problems and argue that overcoming them requires a fundamental reframing of the role of the state in innovation, from market-fixing to market co-creation and co-shaping, in which risks and rewards are shared across a symbiotic public-private relationship.
\end{abstract}

\section{Introduction}

Countries across the world recognise the vital importance of both enhancing research and development $(R \& D)$, and ensuring equitable pricing and access to cutting-edge treatments. However, despite delivering numerous therapeutic advances, the existing system of biopharmaceutical innovation suffers from at least four major problems in achieving these goals: a lack of directionality to meet key needs; inefficient collaboration; high prices that fail to reflect the public contribution; and an overly financialised business model. COVID-19 one of the gravest public health challenges in modern times - has magnified and focalized these challenges, as the development, manufacturing, and distribution of effective therapeutics and vaccines are critical to any exit strategy from the pandemic.

In this paper, we review the major problems impacting the biopharmaceutical industry and argue that overcoming them requires a fundamental reframing of the role of the state in innovation, from market-fixing to market co-creation and co-shaping, in which risks and rewards are shared across a symbiotic public-private relationship.

\section{Problems of the existing biopharmaceutical innovation system}


First, many areas of medical need - especially in public health - are unmet and underfinanced. The system is skewed towards revenue-rich ailments. ${ }^{1}$ Diseases relevant to high-income countries are seven to eight times more likely to be investigated than those that mainly affect low- and middle-income countries. ${ }^{2}$ Disease groups that present smaller financial returns are largely overlooked. The development of drugs and vaccines for neglected tropical diseases, for example, accounted for only $1 \%$ of clinical trials registered between 2011 and $2016 .{ }^{3}$ But neglected diseases are not confined to tropical diseases: Central nervous system disorders, a therapeutic area for which there has been low probability of clinical trial success, have been increasingly marginalised from many companies' research and development pipelines, leading to an increasing disconnect between unmet medical need and investment. ${ }^{4}$

Firms also often pursue low-risk strategies that can more easily yield commercial success instead of developing innovations to address unmet needs. Two major strategies to achieve this include ever-greening (extending the monopoly period on a drug by artificially extending the life of a patent or other exclusivity) and developing me-too drugs (drugs that are structurally related to a first-in-class compound and share the same therapeutic purposes, but with only minor differences in the pharmacological profile that provide, at best, incremental innovation). ${ }^{5,6}$ Between 2005 and 2010 nearly $78 \%$ of drugs approved by the United States Food and Drug Administration (FDA) corresponded to existing drugs on the market. ${ }^{5}$. In Europe, an analysis of 1345 new medicine approvals between 2000 and 2014 revealed that $51 \%$ of newly approved medicines were modified versions of existing medicines that did not have evidence of additional health benefits. ${ }^{7}$

Lack of innovation in vaccines against infectious diseases of pandemic potential exemplified by coronaviruses - follows this trend. The emergence and alarming consequences of severe acute respiratory syndrome (SARS) coronavirus in 2002 and Middle East respiratory syndrome (MERS) coronavirus in 2012 were insufficient to spur R\&D efforts on vaccines. Overall coronavirus $R \& D$ funding - mostly from public sources - has been paltry, totalling $\$ 27$ million in 2016 , increasing to $\$ 50$ million in 2017 , and then falling significantly to around $\$ 36$ million in $2018 .^{8}$ Due to a lack of resources, the vaccine $R \& D$ projects launched after the outbreak of SARS-CoV-1 in 2003 were abandoned before they had been successfully completed, despite the availability of a number of promising candidates and an awareness of the risk posed to humans. ${ }^{9-11}$ It took a sweeping pandemic almost two decades later to spur necessary action.

Second, reinforcement of the intellectual property rights (IPR) system has increasingly come at the expense of effective collaboration. The current innovation system, in which the product development and manufacturing processes are increasingly intertwined, is highly 
disintegrated, unsuitable for solving the complex problems that arise from the non-modular nature of biopharmaceutical innovation. ${ }^{12,13}$ As the need for the transfer of knowledge and know-how becomes greater, the constraints of patents for incentivising and facilitating dynamic models of knowledge exchange and production become more evident. As the major incentive for innovation in our current system, the IPR system encourages a protectionist attitude around research, with each actor working in secrecy and isolation. This creates further barriers to addressing the existing insufficiencies in effective and transparent data sharing in both public and private research institutions, ${ }^{14-16}$ which can result in wasted financial resources and duplication of scientific efforts. ${ }^{17-19}$

Additionally, patenting is increasingly too wide (broadly defined patentable subject matter), too strong (hard to licence), and too upstream (privatising the tools for research), so that not only are products being patented, but also the tools and processes for research that might lead to those discoveries. This blocks the ability of new, basic science to be fully disseminated, diffused, and translated into future innovation. ${ }^{20,21}$ For example, the intense patenting activities around the CRISPR-Cas9 (clustered, regularly interspaced, short palindromic repeats and its associated enzymes such as CRISPR-associated protein 9) technology platform for genome editing by different institutions can lead to significant fragmentation of its intellectual property rights landscape; if the knowledge holders cannot find effective ways to cooperate, the potential of this technology could become more limited. This is a classic case of the anticommons problem, in which a resource is prone to underuse when multiple owners each have a right to exclude others from a scarce resource and no one has an effective privilege of use. ${ }^{22}$ This makes the research process less efficient and exposes research and its outcomes to bias in favour of actors' specific interests (be they financial or scientific). Limited sharing of information and tools pertinent to COVID-related health technologies can risk derailing coordinated efforts on clinical trials, creating unnecessary drag to the speed of R\&D and excluding low- and middle-income countries from the process. The societal and economic cost of such delay would be enormous.

Third, high drug pricing forms a major barrier to access to medicines across the world. Even though most treatments are heavily paid for by the taxpayer, with public funds from organisations like the US National Institutes of Health $(\mathrm{NIH})$, when breakthrough treatments do make it to market, they often have price tags that are beyond the reach of the taxpayers themselves. This puts pressure on health systems in high-, middle- and low-income countries. The ability to charge high prices is based on the monopoly protection granted through patents on new drugs. Despite substantial public funding of R\&D - globally, some estimate that the public pays for between one- to two-thirds of upfront drug R\&D costs ${ }^{2}-$ there are no guarantees that drugs developed from publicly funded research will be 
affordable and accessible. Sofobuvir, an antiviral treatment for hepatitis $\mathrm{C}$, provides a notable case of the socialisation of risks and privatisation of rewards. First developed by Pharmasset, the drug benefited significantly from more than 10 years of Veterans Affairsand $\mathrm{NIH}$-funded research at Emory University, as well as from an NIH small business innovation grant. ${ }^{12}$ After its acquisition by Gilead Sciences, the product was priced at about $\$ 90,000$ per three-month course of treatment at launch.

As R\&D efforts for vaccines and treatments for COVID-19 intensify, similar concerns have arisen about their pricing and the extent to which it reflects public contributions. Between 2002 and 2020, the NIH spent nearly $\$ 700$ million on coronavirus R\&D, leading to a number of promising drug candidates. ${ }^{23}$ It is estimated that the public funding for the antiviral treatment remdesivir - also a product from Gilead Sciences - was at least $\$ 70.5$ million as of May $2020 .{ }^{24}$ While Gilead's pricing of the drug - $\$ 3120$ for a five-day treatment course in the United States - is in line with the value-based estimates from the Institute for Clinical and Economic Review (ICER), ${ }^{25}$ this pricing continues to ignore the collective nature of value creation, and the lack of safeguards for drug pricing ex ante, as well as the imbalance in price setting and bargaining power between the public sector and the private sector, remains unchallenged. ${ }^{12}$

Fourth, companies have become overly financialised, limiting reinvestment into production and innovation, and focusing on short-term return. One of the most common symptoms of this problem is the extent to which share buybacks are used, in which companies purchase their own stocks to boost the value of the remaining ones to shareholders in equity markets. ${ }^{26,27}$ From 2007 to 2016, the 19 pharmaceutical companies included in the SandP 500 Index in January 2017 (and publicly listed from 2006 to 2015) spent $\$ 297$ billion repurchasing their own shares, equivalent to $61 \%$ of their combined $R \& D$ expenditures over this period. ${ }^{28}$ At the same time, increasing financialisation contributes to the rising trend of externalisation of R\&D and manufacturing. Big biopharmaceutical firms increasingly disinvest from riskier upstream research and instead focus more on acquiring products from biotech companies that are already in later clinical trial stages. ${ }^{29}$ As biotech start-ups seek to boost market valuation, pushing for high drug pricing becomes an essential approach to project high profitability. ${ }^{30,31}$ High expectations in vaccines for COVID-19 in several biotech companies have seen their share prices more than double..$^{32}$ However, the drive to cut costs by outsourcing manufacturing overseas has come at the cost of local capabilities and the underlying industrial commons. ${ }^{33}$ Coupled with the contraction elsewhere in the world, concentration of manufacturing capacity has substantially reduced the resilience of the supply chain, which is particularly exposed during systemic shocks. Lack of preparedness in manufacturing has led to shortages of drugs essential for managing COVID-19, from pain 
relief for mild symptoms, such as paracetamol, to powerful anaesthetics used to sedate patients on ventilators, such as propofol, midazolam and fentanyl, and, more widely, drugs that were already at risk of shortages before the pandemic, due to lack of financial incentives to market, supply chain vulnerabilities and manufacturing difficulties. ${ }^{34,35}$

\section{From market-fixing to market co-creating and co-shaping}

Addressing these persistent problems in the biopharmaceutical innovation system requires a different framing of the role of the public sector from the one that governments have chosen: that of market fixer. ${ }^{36}$ This role stems from prevailing economic theory, which does not consider the state a key driver of market creation. ${ }^{37,38}$ State intervention is thus justified only in areas characterised by market failures - such as coordination or information failures, ${ }^{39,40}$ imperfect competition, under-provision of positive externalities, over-provision of negative externalities ${ }^{41}$ and under-provision of new knowledge arising from basic research - with actions restricted to levelling the playing field so that industry and competition can thrive; devising market mechanisms to internalise external benefits or costs; and funding basic public goods, such as science, infrastructure and education.

This view has significantly limited policymakers' understanding and choice of tools for addressing problems with the biopharmaceutical innovation system. ${ }^{42,43}$ Governments establish intellectual property rights to consolidate the appropriability of benefits from knowledge production and exchange to incentivise private innovative activities. However, they are reluctant to shape the rules in the public's interest, despite the high social cost of maintaining the status quo. Governments are also reluctant to make strategic choices and build proactive industrial policy agendas, as these are seen as distorting the functioning of the market and crowding out private-sector actors. Instead, governments justify the economic rents and supranormal returns for private investors in innovation as the necessary rewards for high risk-taking, but at the same time they significantly under-play their own, more substantial role in high risk-taking as an investor of first resort throughout the innovation chain, to a lender of last resort. In addition to inflating the return on private investment, governments do not proactively consider the return for the public on the investment in innovation by the public, and instead frame the spending on public goods such as science as de-risking the activities of private innovators.

Yet, throughout the history of capitalism, the state has often been responsible for actively shaping and creating markets, not just fixing them. ${ }^{38}$ The impact of the state's role in investing in the production and translation of scientific knowledge has been well-documented and quantified. It has been demonstrated that over the past 90 years, almost one-third of 
patents in the US have relied on federal research. ${ }^{44}$ In addition, through its innovative institutions, the state has engendered some of the most important general-purpose technologies, from mass production, to aerospace, and information and communications technology. ${ }^{42,45,46}$ The Defense Advanced Research Projects Agency (DARPA) developed foundational technologies for Apple's i-products; the US Navy was behind the development of the global positioning system (GPS); and the Central Intelligence Agency (CIA) created the touchscreen display that is now commonplace. ${ }^{42}$ Importantly, public investments in these examples went beyond any typical 'public good' in market failure theory (Arrow 1962; Nelson 1959). The nature of these investments is not merely a matter of narrative and framing. Multiple well-documented examples from across different sectors and countries have shown that government agencies have funded areas throughout the entire innovation chain: both basic and applied research, and in many cases provided downstream early stage high-risk finance to companies deemed too risky by the private financial sector. ${ }^{42}$ In addition, market co-shaping and co-creation have also occurred through demand-side policy instruments based on mass government procurement programmes (e.g. in semiconductors and in vaccines). Although private investments are crucial to sustaining the level of risk-taking and capital intensity required in innovation, they are conditional on the groundwork laid by the public sector - a fact that has been historically overlooked.

In the biopharmaceutical sector, the public sector has been responsible for funding some of the highest risk research in biomedical R\&D, leading to most innovative and crucial biomedical innovations. ${ }^{47,48}$ Public sector investment often underlies therapeutic advances that are truly innovative and impactful to human health ${ }^{49,50}$ and create positive fiscal impact for the private sector by generating further investments ('crowding in') ${ }^{51,52}$ and substantial drug sales revenue. ${ }^{53}$

\section{Market-shaping approaches to biopharmaceutical innovation}

Realisation of these contributions has critical implications for the distributions of risks and rewards in innovation. ${ }^{54}$ Unlike private investors, who receive tangible financial rewards, the state generally accrues return on its investment through the knowledge spillovers that are created, and via the taxation system due to new jobs being generated, as well as taxes being paid by companies benefiting from the investments. However, public returns through these mechanisms are offset in several ways. First, knowledge spillover is significantly hindered by strong mechanisms of knowledge appropriation. ${ }^{55}$ Second, corporate taxation has been falling globally, and corporate tax avoidance and evasion have been rising. Tax cuts, such as those promoted by the US Tax Cut and Jobs Act of 2017, are touted as an 
incentive to encourage companies to repatriate their overseas capital. However, their intended impact - increased domestic investment in R\&D and job creation - have hardly materialised, while stock buyback and dividends have increased. ${ }^{24}$ Third, in the case of health, the economic, welfare and health benefits of biopharmaceutical innovations are also further deterred by the barriers to accessing innovative treatments posed by high pricing. ${ }^{56,57}$ In this context, the emphasis on maximising financial capital to deliver shareholder value over stakeholder value in the current model of capitalism has served to reinforce the inherent flaws in the risks-rewards nexus, tilting it further towards private financial gains and away from public interest.

Rectifying the balance between risks and rewards requires a new understanding of the role of the state in the governance of biopharmaceutical innovation as a proactive market cocreator and co-shaper: steering innovation, obtaining fair prices, ensuring that patents and competition work as intended, setting conditions for reinvestment and safeguarding medicine supply. In other words, the responsibility to create a more symbiotic relationship with the private sector and an innovation system that aligns with societal benefit significantly rests on the state overcoming the conceptual confines of the market-fixing role.

While no single or straightforward set of policies can thoroughly address all the problems in biopharmaceutical innovation across varying health system contexts, we highlight a subset of practice-based policies that emphasise systemic market-shaping principles and examine briefly the impact of COVID-19 on the progress and prospect for policy implementation.

\section{Deploying mission-oriented innovation}

To direct biopharmaceutical innovation towards public health priorities, the public sector must be guided by a mission-oriented framework, in the same way that it is during war time. Strongly problem-oriented in nature and problem-solving in purpose, the mission-oriented approach to innovation is a way to bridge a top-down agenda driven by societal challenges and bottom-up explorative approaches to deliver innovations in an outcome-focused, milestone-driven and time-constrained manner. ${ }^{58}$ The concept of mission has been adopted as the central construct for policy making in industrial policies, and research and innovation policies, at national and international levels. ${ }^{58,59}$

Unique catalysts for mission-oriented innovation are mission agencies, which enhance the role of the state in coordinating public and private sectors and create new markets by inducing procurement. ${ }^{60,61}$ For example, the ARPA agencies, including the US Defense Advanced Research Projects Agency (DARPA) and Advanced Research Projects Agency Energy (ARPA-E), ${ }^{62,63}$ help strategise innovation investment, harmonise and manage 
horizontal collaboration across sectors and actors, and coordinate the vertical integration of product development. In health, the recently proposed Health Advanced Research Projects Agency (HARPA) offers a feasible model for lean and autonomous bureaucratic structures that provide freedom to pursue blue-sky innovations (and in the process lead to a significant spillout effect on other sectors) while also being driven by outcomes towards specific missions. ${ }^{64}$ The US Biomedical Advanced Research and Development Authority (BARDA) demonstrates another key attribute of mission-oriented agencies in public procurement: when missions create innovative solutions, they also directly create market demand that self-enforces the need for further innovations. ${ }^{61}$

DARPA and BARDA have seeded and directed new technological trajectories in DNA and mRNA vaccine technologies, which may prove to be important platforms for vaccines against COVID-19.65,66 While there is increasing interest in advanced countries in increasing R\&D investment and setting up or broadening the scope of ARPA-type programmes as part of a post-pandemic recovery plan, ${ }^{67}$ it is critical that these programmes are designed and implemented alongside substantial changes in the healthcare and innovation systems that can broaden access to technology, lower pricing, enhance knowledge transfer and connect procurement at an international level, rather than simply focusing on competitive and economic advantages. In addition, innovations should not be confined to a narrow and siloed technological focus, but instead must connect with and strengthen wider public health infrastructures and social innovations. A holistic mission-oriented approach to innovation must take a systems perspective on 'wicked' problems that have complex socio-economic and technological dimensions. This requires the proposals to develop cutting-edge biopharmaceutical technologies to be nested within myriad different moving parts - such as innovations in other aspects of healthcare, infrastructures, social enterprises and institutions - in an inter-related network of actors and institutions, with the overarching goal of generating stronger systemic resilience. ${ }^{68}$ Furthermore, national efforts must be aligned with international efforts to maximise the leverage of international procurement mechanisms (such as Gavi, the Vaccine Alliance) and avoid inefficiency.

\section{Reshaping knowledge governance for public value}

Patents must be seen through a knowledge governance perspective, not an innovation incentive perspective, so that the monopoly profit given to a company during the patent term should be governed to make sure that the patent produces productive entrepreneurship. ${ }^{69}$ On one level, patentability criteria should be made more stringent. To incentivise innovation, patents should protect only the area that is fundamentally new and be focused downstream, so as to avoid tools and processes being privatised, while at the same time enabling 
licensing and diffusion..$^{20,21}$ On another level, governments should more actively use policy instruments designed to uphold equitable knowledge governance and improve access to medicines, especially during public health crises, such as voluntary licencing arrangements (e.g. through Medicines Patent Pools), assertion of government rights over patents (e.g. compulsory licencing under the flexibilities of the Trade-Related Aspects of Intellectual Property Rights, March-in Right under the Bayh-Dole Act) and government patent use (through 28 U.S.C. §1498).

In addition to strengthening the role of the state in enforcing IPR for public health, government should more actively explore and foster alternative models of innovation that better facilitate knowledge exchange, maximise use of existing knowledge and reduce transaction costs. Open innovation, which can be generally defined as 'the process of innovating with others for shared risk and reward to produce mutual benefits for each organisation, creating new products, processes or ideas that could not otherwise have been achieved alone, or enabling them to be achieved more quickly, cheaply or efficiently,' 70 describes an important group of models. Although the willingness of private sector collaborators to abdicate the pursuit and control of IPR varies, loosening the constraint imposed by IPR is a key element of the various forms of open innovation in general. ${ }^{71}$ While some models are better characterised as public-private partnerships, where only the research problem is in the public domain and the solutions remain subject to the structures of IPR, ${ }^{72}$ other models have sought to establish a norm of collaboration and sharing in the absence of patents, and these have demonstrated the potential to create flexible forms of market-creating collaboration beyond simply buttressing the classic market-fixing and derisking stereotype for public sector.

The need to address disease spaces that lack economic incentives - especially infectious diseases - has led to the creation of not-for-profit product development partnerships, such as the Drugs for Neglected Diseases initiative, the Global Antibiotic Research and Development Partnership, the Medicines for Malaria Venture and the Global Alliance for Tuberculosis Drug Development. These models channel public and private efforts into delivering specific target product profiles that represent public R\&D priorities, and explicitly set out IPR policies that ensure the sharing of patented knowledge and affordable access to the resultant products. ${ }^{71}$ On the patent-free end of the spectrum, open science - exemplified by the Structural Genomics Consortium ${ }^{73}$ and the Open Source Drug Discovery project ${ }^{74}$ provides a model for building platforms for knowledge commons that would not have been permitted under the patent system, and for illuminating possible routes for the open source drug development of the future, whereby new drugs can be taken all the way from basic research to clinical trials without the filing of patents. ${ }^{72}$ 
In tackling COVID-19, countries are increasingly aware of the potential of compulsory licensing. For example, Israel issued compulsory licensing to enable the import of generic alternatives to lopinavir/ritonavir due to concerns over their supply (rather than their pricing, which is a more common rationale for invoking compulsory licensing).${ }^{75}$ Several other countries, including Chile, Ecuador, Canada and Germany, have also initiated legal and legislative steps to create a national framework for the use of compulsory licensing to facilitate access to health products and other technologies for managing COVID-1975,76. At the same time, new policy instruments exemplified in the WHO COVID Technology and Access Pool (C-TAP) provide an enabling platform for voluntary sharing of data, know-how and patents related to any COVID-related health technology. ${ }^{77,78}$ Beyond its public interest case, C-TAP has a robust economic case: the quicker effective vaccines, therapeutics and diagnostics become available, the quicker the world can exit from the pandemic and minimise its damage. Despite their support for more conventional public-private partnerships at global and national levels, major advanced countries, non-profit funders and the biopharmaceutical industry (bar two executives) have chosen to distance themselves from the more transformative C-TAP. In particular, the industry has dismissed and distorted the basic rationale of the initiative - a voluntary sharing mechanism that protects patents and allow companies to retain control over critical technologies and data - to one that threatens existing IPR. Given the determination of the biopharmaceutical industry to buttress the existing IPR regime, prospects for genuinely transformative open innovation projects to scale at a systems level may remain challenging. To build greater leverage and more meaningful dialogue, public funders must formulate and enforce conditionalities on publicly funded $R \& D$, which is covered next.

\section{$\underline{\text { Putting in place conditionalities for public interest }}$}

Government agencies must put in place conditionalities for public return when making public investment into biopharmaceutical innovation and procurement. To ensure that the public contribution to biopharmaceutical R\&D is taken into account in price setting ex ante, conditions on affordability and access must be attached to public funding. Commitment of the public sector to ensuring public return must be brought back. In 1995, NIH rescinded a 'fair pricing clause' in its collaboration and licensing arrangements under its Cooperation Research and Development Agreement (CRADA), which sought to ensure fair pricing of products resulting from public funding, in an attempt to ease the fears of private sector collaborators and stimulate commercialisation. ${ }^{79}$ Given that the outsourcing model of innovation has led the private sector to rely more heavily on publicly funded $R \& D$, a revised clause updated for the current innovation context with better clarity, more consistent 
application, broader scope, and clearer indication of the reward for genuine innovation could have significant potential to ensure affordability of innovative products. ${ }^{80}$ Additionally, conditions can include commitment for reinvestment of a share of the company's profits into productive economic activities or a public innovation fund..$^{42}$

Additionally, the public sector can more proactively manage its ownership of IPR, and its associated knowledge and financial returns, whether by retaining stakes in the companies concerned, holding intellectual property rights or receiving royalties on sales. While public funding should encourage open access to data and knowledge where possible, governments could also retain a 'golden share' of patents developed with public funding, with patents governed in such a way as to allow companies to recover their costs while spurring greater use of that specific innovation. Ultimately, such a 'golden share' would allow the public to convert a property right previously granted into a general public licence, should the owner refuse to license broadly and fairly. ${ }^{69}$ Royalties can be used to finance future innovation or to help cover the losses that inevitably arise when investing in high-risk areas. ${ }^{81-83}$

The highly substantial public investments in the R\&D of COVID-19-related health technologies have put conditionalities into much sharper relief. ${ }^{84}$ Underpinned by the rationale to create a symbiotic relationship between public and private actors in the context of COVID-19, 140 public figures, including 50 former world leaders, have led the call for a 'people's vaccine': a 'global guarantee which ensures that, when a safe and effective vaccine (and other technologies for COVID-19) is developed, it is produced rapidly at scale and made available for all people, in all countries, free of charge' (Khan, Ramaphosa et al. 2020).

Yet, even though the arguments for conditionalities are strong, their substantive relevance remains finely in the balance in the complex political economy of biopharmaceutical innovation. It remains to be seen whether any high-profile public-private partnerships at global and national levels will make firmer and more specific commitments that enable vaccines to be universally available according to need and free at the point of use, beyond commonplace statements of principle and generic pledges. At the same time, it is essential that these partnerships be more transparent about negotiations on pricing, procurement and potential conflict of interests. Mismanagement of issues around these areas will damage public trust and public health. Nevertheless, increased willingness for state investment to translate into partial public ownership of companies and/or their public-funded innovations partly driven by nationalistic concerns - may open up new policy opportunities for the state to shape the pricing, manufacturing and distribution of vaccines. 


\section{De-financialising biopharmaceutical innovation: corporate governance reform and}

manufacturing revival

Large pharmaceutical companies have become overly financialised in recent decades. Active measures can be taken to promote corporate governance models that share that value fairly between all stakeholders, not just shareholders. ${ }^{86}$ While the pharmaceutical sector remains one of the most financialised industries, short-termism and financialisation are not unique to biopharmaceutical innovation, and reforms to corporate governance must apply to the wider economy as a whole. Initial measures can focus on addressing the symptoms of shareholder value. Limiting the practice of share buybacks for firms that have benefited from publicly funded research is a first step. In the US, companies have been allowed to repurchase their shares on the open market with virtually no regulatory limits since $1982 .{ }^{87}$ Shifting managerial incentives away from share buyback requires executive compensation to be based on means other than stocks. In the case of pharmaceutical companies, new rules can require that any performance-related bonuses reward, for example, the success of the company in generating new medicines that deliver therapeutic advance, at affordable prices.

Deeper reforms to align corporate governance with public values involve ensuring companies incorporate public interest into their ethos, decisions and actions. One possible approach is to place stakeholders representing taxpayers, workers and patients directly on corporate boards of publicly listed pharmaceutical companies. Governments could encourage or mandate companies to allocate a certain number of board positions to such stakeholder representatives. Another approach is to amend the legal duties of all company directors so that they are obliged to serve the interests of a range of stakeholders, rather than to prioritise shareholders. These two approaches can go hand in hand. ${ }^{88}$ Reforms geared towards increasing productive investments - for example, prohibiting share buybacks or setting conditionality of reinvestment - can play a vital role in reversing the vicious cycle caused by financialisation. ${ }^{89}$

In addition, to nurture a resilient and responsive industrial ecosystem capable of ramping up production during crisis times, countries must take the lead in actively building and buttressing public manufacturing capabilities across a range of sectors critical to essential medical supplies, from PPE, ventilators and testing to biopharmaceutical products. ${ }^{90}$ Across all countries, stronger global supply chain resilience has to be built upon stronger local productive capacity and the regeneration of industrial commons - the collective capabilities and infrastructures of 'R\&D know-how, advanced process development and engineering skills, and manufacturing competencies related to a specific technology' resulting from the clustering of upstream and downstream actors from both public and private sectors. ${ }^{89,91,92}$ 
The measures in these areas are far-reaching and will require deep restructuring of the relationships between finance, productive activities and labour. With regard to definancialisation, states have learned lessons from the previous financial crisis, and are more willing to impose bail-out conditions with restrictions on share buyback and executive pay. However, the implications of these broader developments on the over-financialised biopharmaceutical industry is difficult to ascertain. Biopharmaceutical stocks have weathered the storm well relative to the overall market and have become the centre of speculation. ${ }^{32}$ The industry itself is keenly aware of its highly critical role in the pandemic, and will likely tread on the economic and political issues pertinent to vaccines and treatments, and manage its role in serving commercial, national and global interests in order to resist any systematic shock to its business model with caution, especially in the moments when the momentum for change is greatest. Sustained, intense public scrutiny and advocacy across different sectors - health, climate, finance - will be needed to rigorously hold the industry to account and push for systemic change.

In terms of manufacturing, states are driven by current needs and, alerted by the fragilities in the global supply chain, are finally paying long-overdue attention to strengthening local capacities. In the US, this is a policy issue increasingly gaining bi-partisan support, for example Senators Warren and Rubio's legislation to review the pharmaceutical supply chain in the wake of COVID-19. ${ }^{93}$ In the biopharmaceutical sector, the renewed focus on manufacturing will benefit not only innovative products, but also conventional products that are in short supply. There is a strong case for a public option in pharmaceuticals: government-provided, quality-assured medicines that are universally available at a reasonable and fixed price, which coexist with products from the private sector ${ }^{94-96}$ This can range from the creation of a new business model dedicated to creating a functional, competitive market for pharmaceuticals suffering shortages (e.g. Civica $\mathrm{Rx}$ ) to the state becoming directly involved in - and taking a substantial stake in - coordinating and executing the full range of activities in drug innovation and manufacturing in order to retain a sufficient level of control. ${ }^{97}$ As persistent market failures, and a lack of political and economic imagination in finding solutions beyond creating and aligning incentives for the private market to address the gaps in innovation and pharmaceutical supply, become a repeated phenomenon, the drive to marry innovation, manufacturing and social policies may well provide new impetus for public-sector solutions.

\section{Conclusion}


How the public sector governs the health innovation system and creates symbiotic publicprivate relationships will come to define the innovation-led welfare state of the 21 st century. The COVID-19 pandemic has presented a critical window and created significant momentum for states to move away from market-fixing approaches to biopharmaceutical innovation towards market-shaping approaches. At a global level, states will need to make joint efforts to impose firm IPR, pricing and manufacturing rules that are designed and enforced in ways that value international collaboration and solidarity, rather than competition, between countries. Key concerns about the impact of these initiatives and their prognosis beyond the pandemic remain. At their core is a question: can the public sector finally rise to the challenge to reset its relationship with the private sector and prepare societies for even sterner tests to come? This requires a change in its remit, governance and the ways in which it understands and assesses 'value'. We hope the paper can inform this process. 


\section{References}

1. Barrenho, E., Miraldo, M. and Smith, P. C. (2019). Does global drug innovation correspond to burden of disease? The neglected diseases in developed and developing countries. Health Economics, .28 (1), pp. 123-143. DOI:10.1002/hec.3833

2. Røttingen, J. A. et al. (2013). Mapping of available health research and development data: What's there, what's missing and what role is there for a global observatory? Lancet, 382, pp. 1286-1307.

3. Pedrique, B. et al. (2013). The drug and vaccine landscape for neglected diseases (2000-11): A systematic assessment. Lancet Global Health, 1, e371-9.

4. Dowden, H. and Munro, J. (2019). Trends in clinical success rates and therapeutic focus. Nature reviews. Drug discovery, 18, pp. 495-496.

5. Feldman, R. (2017). May Your Drug Price Be Ever Green. Oxford Journal of Law and the Biosciences. DOI:10.2139/ssrn.3061567

6. Aronson, J. K. and Green, A. R. (2020). Me-too pharmaceutical products: History, definitions, examples, and relevance to drug shortages and essential medicines lists. British Journal of Clinical Pharmacology. DOI:10.1111/bcp.14327

7. New drugs and indications in 2014: Some advances this year, but many drugs are poorly evaluated too expensive, or more dangerous than useful. (2015). Prescrire International, 24, pp. 107-110.

8. Plüss, J. D. (2020). With no prospects for profits, big pharma neglects new infectious diseases. SWI swissinfo.ch. Available at: https://www.swissinfo.ch/eng/covid-19_withno-prospects-for-profits--big-pharma-turns-back-on-new-infectiousdiseases/45598436. (Accessed: 17th September 2020).

9. Menachery, V. D. et al. (2015). A SARS-like cluster of circulating bat coronaviruses shows potential for human emergence. Nature Medicine, 21, pp. 1508-1513.

10. Chen, W. H., Strych, U., Hotez, P. J. and Bottazzi, M. E. (2020). The SARS-CoV-2 vaccine pipeline: An overview. Current Tropical Medicine Reports, 7, pp. 61-64.

11. OECD. (2020). Treatments and a vaccine for COVID-19: the need for coordinating policies on $R \& D$, manufacturing and access, OECD.

12. Mazzucato, M. and Roy, V. (2019). Rethinking value in health innovation: from mystifications towards prescriptions. Journal of Economic Policy Reform, 22, pp. 101119.

13. Pisano, G. P. (2006). Science business: the promise, the reality, and the future of 
biotech. Harvard Business School Press.

14. Miller, J. E., Wilenzick, M., Ritcey, N., Ross, J. S. and Mello, M. M. (2017). Measuring clinical trial transparency: An empirical analysis of newly approved drugs and large pharmaceutical companies. BMJ Open, 7(12), e17917.

15. Miller, J. E., Korn, D. and Ross, J. S. (2015). Clinical trial registration, reporting, publication and FDAAA compliance: A cross-sectional analysis and ranking of new drugs approved by the FDA in 2012. BMJ Open 5(11), e009758.

16. Chen, R. et al. (2016). Publication and reporting of clinical trial results: Cross sectional analysis across academic medical centers. BMJ, 352, i637.

17. Al-Shahi Salman, R. et al. (2014). Increasing value and reducing waste in biomedical research regulation and management. Lancet 383, pp. 176-185.

18. Dijkers, M. (2019). Reduce, reuse, recycle: good stewardship of research data. Spinal Cord, 57, pp. 165-166.

19. Owens, B. (2016). Data sharing: Access all areas. Nature 533, S71-S72.

20. Mazzoleni, R. and Nelson, R. R. (1998). Economic theories about the benefits and costs of patents. Journal of Economic Issues, 32, pp. 1031-1052.

21. Orsi, F., Sevilla, C. and Coriat, B. (2006). Upstream patents and public health: The case of genetic testing for breast cancer. In: eds., Mazzucato, M. and Dosi, G., Knowledge Accumulation and Industry Evolution: The Case of Pharma-Biotech. Cambridge University Press, pp. 327-345. DOI:10.1017/CBO9780511493232.011.

22. Heller, M. A. and Eisenberg, R. S. (1998). The tragedy of the commons. Science, (80-. ). 162, pp. 1243-1248.

23. Rizvi, Z. (2020). Blind Spot: How the COVID-19 outbreak Shows the Limits of Pharma's Monopoly Model. Available at: https://www.citizen.org/article/blind-spot/.

24. Public Citizen. The real story of Remdesivir. (2020). Available at: https://www.citizen.org/article/the-real-story-of-remdesivir/. (Accessed: 3 October 2020).

25. Institute for Clinical and Economic Review. ICER comments on Gilead's pricing for Remdesivir. (2020). Available at: https://icer-review.org/blog/icer-comments-ongileads-pricing-for-remdesivir/. (Accessed: 5 October 2020).

26. Lazonick, W., Hopkins, M., Jacobson, K., Sakinc, M. and Tulum, O. (2017). US Pharma's Financialized Business Model. Institute for New Economic Thinking Working Paper Series No. 60. DOI:10.2139/ssrn.3035529 
27. Collington, R. (2020). Profits, Innovation and Financialization in the Insulin Industry. Institute for New Economic Thinking Working Paper Series 1-36.

DOI:10.36687/inetwp120

28. Tulum, Ö. and Lazonick, W. (2018). Financialized corporations in a national innovation system: The U.S. Pharmaceutical Industry. International Journal of Political Economy, 47, pp. 281-316.

29. Arora, A. and Gambardella, A. (1995). The Division of Innovative Labor in Biotechnology. In: Sources of Medical Technology: Universities and Industry, pp. 188-206.

30. Roy, V. and King, L. (2016). Betting on hepatitis C: How financial speculation in drug development influences access to medicines. BMJ, 354.

31. Birch, K. (2017). Rethinking value in the bio-economy: Finance, assetization, and the management of value. Science, Technology and Human Values, 42, pp. 460-490.

32. Whitfill, T. (2020). Biopharma companies are taking advantage of their misinformation. STAT. Available at: https://www.statnews.com/2020/05/26/biopharma-companiesspreading-misinformation-taking-advantage-of-it/ (Accessed: 28 May 2020).

33. Andreoni, A. and Chang, H. J. (2016). Industrial policy and the future of manufacturing. Economia e Politca Industriale, 43, pp. 491-502.

34. Badreldin, H. A. and Atallah, B. (2020). Global drug shortages due to COVID-19: Impact on patient care and mitigation strategies. Research in Social and Administrative Pharmacy. DOI:10.1016/j.sapharm.2020.05.017.

35. Ouellette, L. L., Price, N., Sachs, R. and Sherkow, J. (2020). How can the US address coronavirus drug shortages? Written Description. Available at:

https://writtendescription.blogspot.com/2020/04/how-can-us-address-coronavirusdrug.html (Accessed: 18 September 2020).

36. Mazzucato, M. (2020). The Covid-19 crisis is a chance to do capitalism differently. The Guardian. Available at:

https://www.theguardian.com/commentisfree/2020/mar/18/the-covid-19-crisis-is-achance-to-do-capitalism-differently (Accessed: 28 May 2020).

37. Arrow, K. J. (1972). Economic welfare and the allocation of resources for invention. In: Readings in Industrial Economics. Macmillan Education UK, pp. 219-236. DOI:10.1007/978-1-349-15486-9_13.

38. Mazzucato, M. (2016). From market fixing to market-creating: a new framework for innovation policy. Industry and Innovation, 23, pp. 140-156. 
39. Stiglitz, J. E. and Weiss, A. (1981). Credit Rationing in Markets with Rationing Credit Information Imperfect. American Economic Review 71, pp. 393-410.

40. Coase, R. H. (1960). The Problem of Social Cost. Source: Journal of Law and Economics 3.

41. Stern, N. (2007). The Economics of Climate Change: The Stern Review. Cambridge University Press.

42. Mazzucato, M. (2013). The Entrepreneurial State : Debunking Public vs. Private Sector Myths. Penguin Books. DOI:10.1016/S1386-6532(09)70080-0

43. Mazzucato, M. (2017). The Value of Everything: Making and Taking in the Global Economy. Allen Lane. DOI:10.1084/jem.20030973

44. Fleming, L., Greene, H., Li, G., Marx, M. and Yao, D. (2019). Government-funded research increasingly fuels innovation. Science (80-. ). 364, pp. 1139-1141.

45. Ruttan, V. W. 2006). Is War Necessary for Economic Growth?: Military Procurement and Technology Development. Oxford University Press.

DOI:10.1093/0195188047.001.0001.

46. Block, F. and Keller, M. (2011). State of Innovation: The U.S. Government's Role in Technology Development. Choice Reviews Online 48, 48-3394.

47. Nayak, R. K., Avorn, J. and Kesselheim, A. S. (2019). Public sector financial support for late stage discovery of new drugs in the United States: Cohort study. BMJ 367.

48. Lazonick, W. and Mazzucato, M. (2013). The risk-reward nexus in the innovationinequality relationship: Who takes the risks? Who gets the rewards? Industrial and Corporate Change, 22, pp. 1093-1128.

49. Sampat, B. N. and Lichtenberg, F. R. (2011). What are the respective roles of the public and private sectors in pharmaceutical innovation? Health Affairs, 30, pp. 332339.

50. Stevens, A. J. et al. (2011). The role of public-sector research in the discovery of drugs and vaccines. New England Journal of Medicine, 364, pp. 535-541.

51. Sussex, J. et al. (2016). Quantifying the economic impact of government and charity funding of medical research on private research and development funding in the United Kingdom. BMC Medicine, 14, 32.

52. Deleidi, M., Mazzucato, M. and Semieniuk, G. (2020). Neither crowding in nor out: Public direct investment mobilising private investment into renewable electricity projects. Energy Policy 140, 111195. 
53. Azoulay, P., Graff Zivin, J. S., Li, D. and Sampat, B. N. (2018). Public R\&D Investments and Private-sector Patenting: Evidence from NIH Funding Rules. Review of Economic Studies, 86, pp. 117-152.

54. Laplane, A. and Mazzucato, M. (2020). Socializing the risks and rewards of public investments: Economic, policy, and legal issues. Research Policy X2, 100008.

55. Nelson, R. R. and Winter, S. G. 1982). An Evolutionary Theory of Economic Change. Belknap Press of Harvard University Press.

56. Hoffman, S. J. and Outterson, K. (2015). What will it take to address the global threat of antibiotic resistance? Journal of Law, Medicine and Ethics, 43, pp. 363-368.

57. Kesselheim, A. S., Avorn, J. and Sarpatwari, A. (2016). The high cost of prescription drugs in the United States origins and prospects for reform. JAMA - Journal of the American Medical Association, 316, pp. 858-871.

58. Mazzucato, M. (2018). Mission-Oriented Research and Innovation in the European Union: A problem-solving approach to fuel innovation-led growth. European Commission. DOI:10.2777/36546.

59. Department for Business Energy and Industrial Strategy. (2017). Industrial Strategy: Building a Britain fit for the future. Department for Business Energy and Industrial Strategy. DOI:10.1049/ir:19930092.

60. Mowery, D. C., Nelson, R. R. and Martin, B. R. (2010). Technology policy and global warming: Why new policy models are needed (or why putting new wine in old bottles won't work). Research Policy, 39, pp. 1011-1023.

61. Edler, J. and Georghiou, L. (2007). Public procurement and innovation: Resurrecting the demand side. Research Policy, 36, pp. 949-963.

62. Mowery, D. C. (2010). Military R\&D and innovation. Handbook of the Economics of Innovation 2, pp. 1219-1256.

63. Bonvillian, W. B. (2018). DARPA and its ARPA-E and IARPA clones: A unique innovation organization model. Industrial and Corporate Change, 27, pp. 897-914.

64. UCL Institute for Innovation and Public Purpose. (2018). The people's prescription: Re-imagining health innovation to deliver public value. IIPP Policy Report. IIPP, Global Justice Now, Just Treatment and STOPAIDS.

65. Pardi, N., Hogan, M. J., Porter, F. W. and Weissman, D. (2018). Vaccines prevent many millions of illnesses and save numerous lives every year. Nat. Publ. Gr., 17.

66. Hodgson, J. (2020). The pandemic pipeline. Nature Biotechnology, 38, pp. 523-532. 
67. Office of the Senate Democrats. (2020). The Endless Frontier Act, introduced by Senate Democratic Leader Chuck Schumer (D-NY), Senator Todd Young (R-IN), Congressman Ro Khanna (D-CA), and Congressman Mike Gallagher (R-WI).

68. UCL Commission for Mission-Oriented Innovation and Industrial Strategy. (2019). A Mission-Oriented UK Industrial Strategy 106.

69. Burlamaqui, L., Castro, A. C. and Kattel, R. (2011). Knowledge Governance: Reasserting the Public Interest. DOI:10.7135/UPO9780857285522

70. Pigott, R., Barker, R., Kaan, T. and Roberts, M. (2014). Shaping the Future of Open Innovation: A Practical Guide for Life Sciences Organisations.

71. Lezaun, J. and Montgomery, C. M. M. (2015). The pharmaceutical commons: Sharing and exclusion in global health drug development. Science, Technology and Human Values, 40, pp. 3-29.

72. Balasegaram, M. et al. (2017). An open source pharma roadmap. PLoS Medicine, 14, e1002276.

73. Bountra, C., Lee, W. H. and Lezaun, J. (2017). A New Pharmaceutical Commons: Transforming Drug Discovery. Oxford Martin Policy Paper.

74. Årdal, C. and Røttingen, J. A. (2012). Open source drug discovery in practice: A case study. PLoS Neglected Tropical Diseases 6, e1827.

75. Wong, H. (2020). The case for compulsory licensing during COVID-19. Journal of Global Health, 10.

76. Bassi, L. L. and Hwenda, L. (2020). COVID-19: Time to plan for prompt universal access to diagnostics and treatments. Lancet Global Health 8, e756-e757.

77. Nature Editorials. (2020). Coronavirus: everyone wins when patents are pooled. Nature, 581, p. 240.

78. World Health Organization. COVID-19 technology access pool. (2020). Available at: https://www.who.int/emergencies/diseases/novel-coronavirus-2019/global-researchon-novel-coronavirus-2019-ncov/covid-19-technology-access-pool (Accessed: 1 June 2020).

79. Schacht, W. H. (2011). Federal R\&D, Drug Discovery, and Pricing: Insights from the $\mathrm{NIH}-$ University-Industry Relationship.

80. Sarpatwari, A., LaPidus, A. K. and Kesselheim, A. S. (2020). Revisiting the national institutes of health fair pricing condition: Promoting the affordability of drugs developed with government support. Ann.als of Internal Medicine, 172, pp. 348-350. 
81. Brumfiel, G. (2008). Bell Labs bottoms out. Nature, 454, p. 927.

82. Eliasson, G. (2011). Advanced purchasing, spillovers and innovative discovery. Journal of Evolutionary Economics, 21, pp. 121-139.

83. Da Fonseca, E. M., Shadlen, K. and Bastos, F. I. (2019). Integrating science, technology and health policies in Brazil: Incremental change and public health professionals as agents of reform. Journal of Latin American Studies, 51, pp. 357377.

84. Mazzucato, M. and Torreele, E. (2020). How to develop a COVID-19 vaccine for all. Project Syndicate. Available at: https://www.projectsyndicate.org/commentary/universal-free-covid19-vaccine-by-mariana-mazzucatoand-els-torreele-2020-04 (Accessed: 28 May 2020).

85. Khan, I., Ramaphosa, C. and et al. (2020). Uniting behind a people's vaccine against COVID-19. Available at:

https://www.unaids.org/en/resources/presscentre/featurestories/2020/may/20200514_ covid19-vaccine-open-letter.

86. Lazonick, W. and Tulum, Ö. (2011). US biopharmaceutical finance and the sustainability of the biotech business model. Research Policy, 40, pp. 1170-1187.

87. Lazonick, W. (2014). Profits without prosperity: Stock buybacks manipulate the market and leave most Americans worse off. Harvard Business Review.

88. Warren, E. (2018). Text - S.3348 - 115th Congress (2017-2018): Accountable Capitalism Act..

89. Chang, H. and Andreoni, A. (2020). Industrial Policy in the 21st Century. Development and Change, 51 (2), pp. 324-351. DOI:10.1111/dech.12570.

90. Office of U.S. Senator Elizabeth Warren of Massachusetts. (2020). COVID-19 Emergency Manufacturing Act of 2020, introduced by Senator Elizabeth Warren (DMA) and Representative Jan Schakowsky (D-IL).

91. Pisano, G. P. and Shih, W. C. (2012). Producing Prosperity: Why America Needs a Manufacturing Renaissance. Harvard Business Press.

92. Andreoni, A. (2018). The architecture and dynamics of industrial ecosystems: Diversification and innovative industrial renewal in Emilia Romagna. Cambridge Journal of Economics, 42, pp. 1613-1642.

93. Bowden, J. Rubio, Warren to introduce pharmaceutical supply chain review legislation. (2020). The Hill. Available at: 
https://thehill.com/homenews/senate/505188-rubio-warren-to-introducepharmaceutical-supply-chain-review-measure-report (Accessed: 3 October 2020).

94. Mazzucato, M., Li, H. L. and Darzi, A. (2020). Is it time to nationalise the pharmaceutical industry? BMJ, 368, m769.

95. Sitaraman, G. and Alstott, A. L. (2019). The Public Option: How to Expand Freedom, Increase Opportunity, and Promote Equality. Harvard University Press.

96. Brown, D. (2019). Medicine for All: The Case for a Public Option in the Pharmaceutical Industry. Available at: https://thenextsystem.org/medicineforall.

97. Singer, A. C., Kirchhelle, C. and Roberts, A. P. (2019). (Inter)nationalising the antibiotic research and development pipeline. Lancet Infectious Diseases.

DOI:10.1016/S1473-3099(19)30552-3. 